\title{
KAJIAN PENGEMBANGAN BUDIDAYA RUMPUT LAUT DI KAWASAN MINAPOLITAN KABUPATEN SUMBAWA BARAT, NUSA TENGGARA BARAT
}

\author{
Erlania dan I Nyoman Radiarta \\ Pusat Penelitian dan Pengembangan Perikanan Budidaya \\ Jl. Ragunan 20, Pasar Minggu, Jakarta Selatan 12540 \\ E-mail: erlania_ellen@yahoo.com
}

(Naskah diterima: 17 Maret 2014; Revisi final: 30 April 2014; Disetujui publikasi: 3 Juni 2014)

\begin{abstract}
ABSTRAK
Kabupaten Sumbawa Barat telah ditetapkan sebagai kawasan minapolitan untuk pengembangan komoditas rumput laut. Pelaksanaan program minapolitan membutuhkan dukungan data dan informasi yang terbaru mengenai profil, potensi, dan kondisi daya dukung lingkungan. Kajian ini bertujuan menganalisis potensi kawasan minapolitan Kabupaten Sumbawa Barat untuk budidaya rumput laut, Kappaphycus alvarezii, dengan metoda apung dan lepas dasar. Parameter penting kualitas perairan yang berpengaruh terhadap pengembangan budidaya rumput laut telah dikumpulkan meliputi parameter fisik dan kimia perairan. Data sekunder juga digunakan dalam penelitian ini, meliputi peta rupa bumi, citra satelit, dan peta kedalaman perairan. Hasil pengukuran kualitas perairan menunjukkan kisaran yang sesuai untuk pengembangan budidaya rumput laut. Kondisi kelembagaan dan infrastruktur juga mendukung bagi pengembangan kawasan minapolitan rumput laut. Analisis spasial kesesuaian lahan budidaya rumput laut menunjukkan bahwa dari total area potensial sebesar 16.846 ha diperoleh tingkat kesesuaian lahan dengan kategori sangat sesuai untuk budidaya rumput laut sistem lepas dasar sebesar $43,84 \%$ dan sistem apung sebesar $46,77 \%$. Kawasan tersebut tersebar di bagian barat dan utara lokasi penelitian. Strategi yang dapat dilakukan di kawasan minapolitan untuk pengembangan budidaya rumput laut antara lain penentuan lokasi kebun bibit rumput laut, identifikasi dan penentuan musim tanam, penerapan tata guna lahan yang sesuai, serta peningkatan peran penyuluh dan dinas kelautan dan perikanan setempat.
\end{abstract}

KATA KUNCI: $\quad$ budidaya rumput laut, kesesuaian lahan, minapolitan, Sumbawa Barat

ABSTRACT: The assessment of seaweeds aquaculture development in minapolitan area of West Sumbawa Regency, West Nusa Tenggara. By: Erlania and I Nyoman Radiarta

West Sumbawa Regency has been determined as minapolitan area for seaweeds aquaculture development. Implementation of minapolitan program needs recent data and information about profile, potencies, and carrying capacity condition. This study was aimed to analyze potencies of minapolitan area in West Sumbawa Regency for seaweeds aquaculture, Kappaphycus alvarezii, using long-line and off-bottom system. Several important water quality parameters which related to seaweed cultivation were meassured in the field including physical and chemical parameters. Secondary data were also collected such as topography maps, satelite remote sensing, and bathymetry maps. The results showed that water quality parameters in the study area was still suitable for seaweeds aquaculture development. Institutional and infrastructure conditions were also support development of seaweeds aquaculture in this area. Site suitability analysis for seaweed aquaculture showed that from the total potential area of $16.846 \mathrm{ha}$, the most suitable areas was identified about $43,84 \%$ for off-bottom or $46,77 \%$ for long-line culture system. Those area were distributed in west and north part of study site. Several strategies that could be implemented for development of seaweed aquaculture in minapolitan area, included determination of seaweeds nursery locations, identification and determination of seasonal planting periods, implementation of appropriate regional land use, and also role enhancement of aquaculture technical assistant from local government institutions.

KEYWORDS: $\quad$ seaweeds aquaculture, site suitability, minapolitan, West Sumbawa

\section{PENDAHULUAN}

Program peningkatan produksi perikanan budidaya di Indonesia melalui program minapolitan telah menetapkan beberapa komoditas unggulan, diantaranya rumput laut. Produksi rumput laut di Indonesia mengalami peningkatan yang sangat signifikan yaitu sekitar 3.000 ton di tahun 2000 menjadi 2,8 juta ton di tahun 2009 (Ditjen Perikanan Budidaya, 2010). Peningkatan produksi tersebut terus diupayakan guna mencapai sasaran produksi yang telah dicanangkan melalui program minapolitan yaitu sebesar 10 juta ton ditahun 2014. Untuk 
mencapai target produksi tersebut, pemanfaatan sumberdaya lahan yang ada harus dapat diberdayakan secara maksimal sesuai dengan konsepsi minapolitan yang ada, yaitu pembangunan ekonomi kelautan dan perikanan berbasis kawasan berdasarkan prinsip-prinsip terintegrasi, efisiensi, berkualitas, dan percepatan. Implementasi dari penetapan kawasan minapolitan ini, telah dituangkan dalam Keputusan Menteri Kelautan dan Perikanan Republik Indonesia No.KEP.18/MEN/2011 tentang Pendoman Umum Minapolitan. Pentingnya pengembangan kawasan minapolitan di Indonesia diindikasikan oleh ketersediaan sumberdaya lahan perikanan yang besar dan tenaga kerja yang murah, telah terbentuknya kemampuan dan pengetahuan pada sebagian besar pembudidaya, jaringan antara sektor hulu dan hilir yang mulai terjalin, dan kesiapan pranata (institusi).

Kabupaten Sumbawa Barat memiliki luas wilayah sekitar $1.849,02 \mathrm{~km}^{2}$, dengan panjang garis pantai sekitar $167,8 \mathrm{~km}$ (BPS Sumbawa Barat, 2010). Produksi perikanan di kabupaten ini masih didominasi dari perikanan tangkap, yaitu sebesar 3.354 ton; sedangkan produksi perikanan budidaya hanya sebesar 472 ton. Potensi perikanan budidaya yang ada dan cukup menjanjikan di kabupaten ini diantaranya adalah budidaya rumput laut. Total potensi kawasan pengembangan budidaya rumput laut sekitar 1.167 ha, namun pemanfaatannya baru mencapai 150 ha. Peningkatan produksi rumput laut di kabupaten ini cukup baik yaitu 1.100 ton pada tahun 2004 menjadi sekitar 7.600 ton pada tahun 2009 (Anonimous, 2011). Kondisi ini memberikan suatu harapan untuk peningkatan produksi yang lebih besar dengan memanfaatkan sumberdaya lahan yang masih tersedia. Surat Keputusan Menteri Kelautan dan Perikanan Republik Indonesia No. KEP.32/MEN/2010, telah menetapkan Kabupaten Sumbawa Barat sebagai kawasan pengembangan minapolitan dengan komoditas pengembangannya adalah rumput laut (Kappaphycus alvarezii). Selain itu, Keputusan Dirjen Perikanan Budidaya No. KEP.70/DJ-PB/2010, menetapkan kawasan minapolitan di kabupaten ini sebagai kawasan percontohan. Secara konstitusional, keputusan tersebut telah mendapat dukungan penuh dari pemda setempat. Melalui keputusan Bupati Sumbawa Barat No. 1011 tahun 2010 telah menetapkan kawasan minapolitan budidaya rumput laut di Kabupaten Sumbawa Barat. Berdasarkan keputusan tersebut, sentra pengembangan budidaya rumput laut berlokasi di Desa Labuhan Kertasari, Kecamatan Taliwang dengan metode lepas dasar. Daerah penyangga (hinterland) kawasan minapolitan terletak di Kecamatan Poto Tano meliputi Desa Poto tano dengan metode budidaya menggunakan sistem apung (long line), Desa Kiantar dengan sistem apung (long line), Desa Tua Nanga dengan sistem lepas dasar dan apung, dan Kecamatan Jereweh yaitu Desa Beru dengan sistem lepas dasar (Anonimous, 2011). Jenis rumput laut yang umumnya dibudidayakan dikawasan minapolitan Sumbawa Barat adalah jenis Kappaphycus alvarezii.
Untuk mendukung pelaksanaan program minapolitan, kawasan pengembangan tersebut harus didukung oleh data dan informasi mengenai profil, potensi, dan kondisi daya dukung lingkungan. Seluruh data tersebut harus diperoleh secara benar dan dianalisis secara akurat. Sistem informasi geografis (SIG) merupakan satu alat analisis spasial yang telah banyak diaplikasi untuk perikanan budidaya (Kapetsky \& Anguilar-Manjarrez, 2007; Anguilar-Manjarrez et al., 2010; Mustafa et al., 2011). SIG tidak hanya menampilkan karakteristik lingkungan yang meliputi kondisi fisik, kimia, dan sosial ekonomi, namun juga dapat melakukan analisis spasial, sehingga dapat menyederhanakan permasalahan dan pemanfaatan waktu yang lebih efektif (Burrough \& McDonnell, 1998). Aplikasi SIG untuk perikanan budidaya di Indonesia telah disajikan secara komprehensif dalam Mustafa et al., 2011.

Kajian ini bertujuan menganalisis potensi wilayah Kabupaten Sumbawa Barat dalam pengembangan kawasan minapolitan untuk budidaya rumput laut (Kappaphycus alvarezii) dengan metoda apung dan lepas dasar. Hasil kajian ini diharapkan dapat memberikan gambaran umum tingkat kesesuaian lahan di Kabupaten Sumbawa Barat sehubungan dengan penentuan lokasi tersebut sebagai kawasan pengembangan minapolitan.

\section{BAHAN DAN METODE}

Kajian ini telah dilakukan di kawasan pengembangan minapolitan Kabupaten Sumbawa Barat (Gambar 1). Lokasi penelitian terbentang pada posisi $8^{\circ} 30^{\circ}-8^{\circ} 45^{\prime}$ Lintang Selatan dan $116^{\circ} 43^{\prime}-116^{\circ} 53^{\prime}$ Bujur Timur. Kabupaten Sumbawa Barat terdiri dari delapan kecamatan, lima kecamatan merupakan kecamatan pantai yaitu Kecamatan Poto Tano, Taliwang, Jereweh, Sekongkang, dan Maluk, sedangkan tiga kecamatan lainnya merupakan kecamatan daratan yaitu: Kecamatan Brang Ene, Brang Rea, dan Seteluk. Karakteristik perairan pantai yang relatif landai dan tenang serta luasnya area pasang surut, merupakan satu potensi yang baik untuk pengembangan budidaya rumput laut baik dengan teknik apung (long line) ataupun lepas dasar.

Penelitian ini dilakukan dengan metode survai pada bulan Agustus 2011. Data penting yang berpengaruh terhadap pengembangan budidaya rumput laut telah dikumpulkan yang terdiri atas data primer dan data sekunder. Data primer meliputi parameter kualitas fisik dan kimia perairan, meliputi kecerahan, kedalaman, suhu, padatan terlarut total (TDS), salinitas, oksigen terlarut, bahan organik total (TOM), pH, nitrat $\left(\mathrm{NO}_{3}-\mathrm{N}\right)$, nitrit $\left(\mathrm{NO}_{2}^{-}\right.$ $\mathrm{N})$, amonia $\left(\mathrm{NH}_{3}-\mathrm{N}\right)$, fosfat $\left(\mathrm{PO}_{4}-\mathrm{P}\right)$, silikat $\left(\mathrm{SiO}_{2}\right)$, dan besi $\left(\mathrm{Fe}^{2+}\right)$. Data sekunder yang digunakan dalam penelitian ini meliputi peta rupa bumi, citra satelit, dan peta kedalaman; serta data statistik kelautan dan perikanan Kabupaten Sumbawa Barat.

Model kesesuaian lahan pengembangan budidaya rumput laut di lokasi penelitian dianalisis secara spasial yang disajikan secara detail dalam Radiarta et al. (2011). 


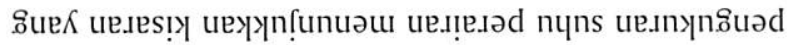

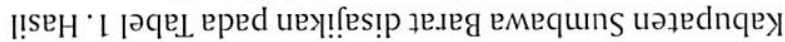

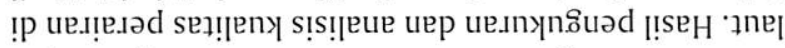

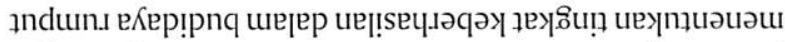

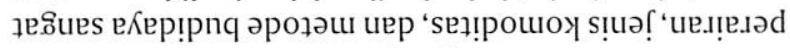

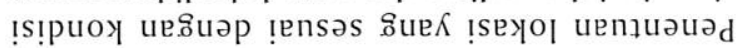

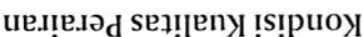

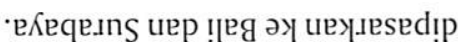

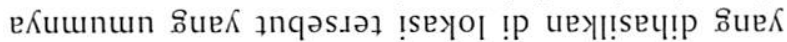

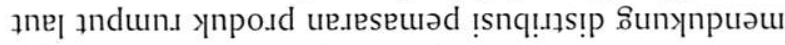

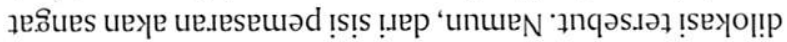

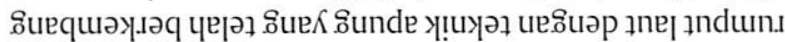

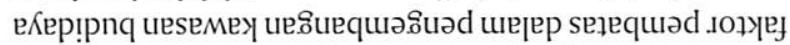

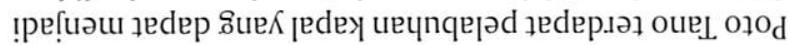

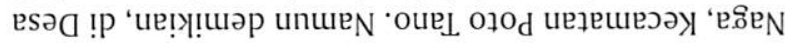

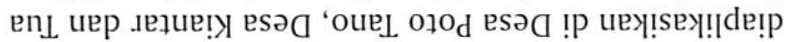

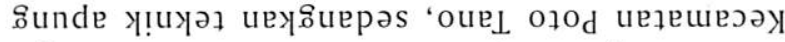

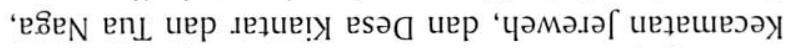

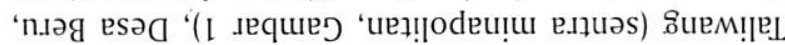

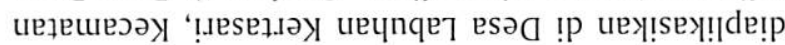

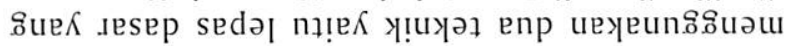

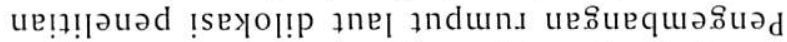

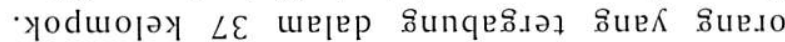

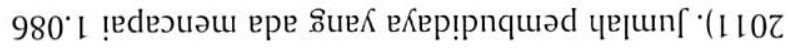

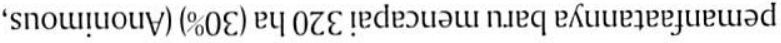

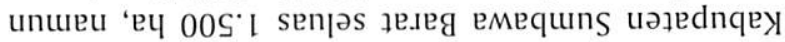

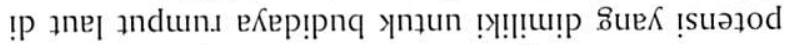
емцея uеуүй

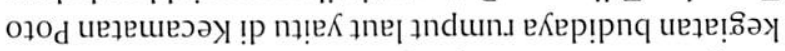
y

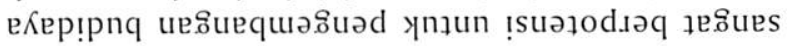

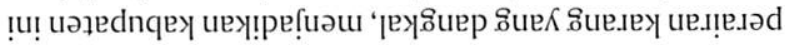

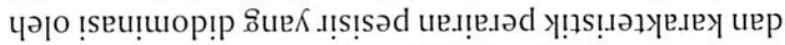

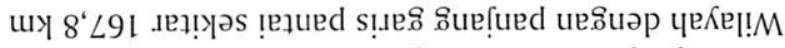

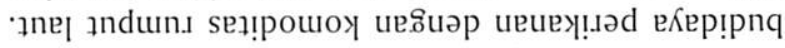

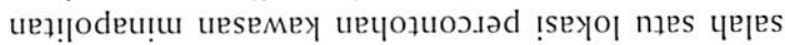

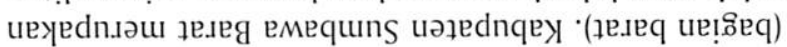

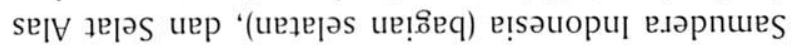
‘(.nu!̣ uep e.ıеın ue!

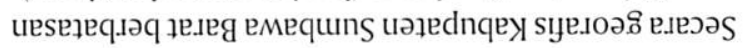

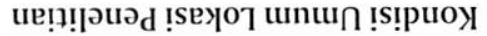

\section{NVSVHVG NVQ TISVH}

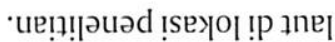

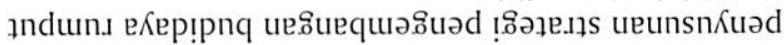

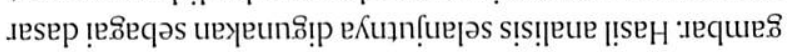

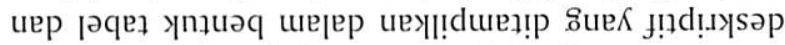

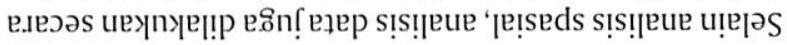

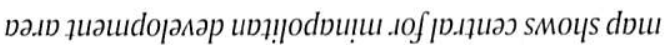

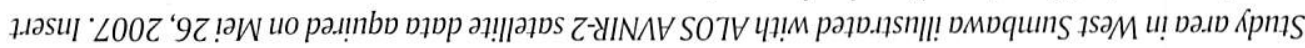

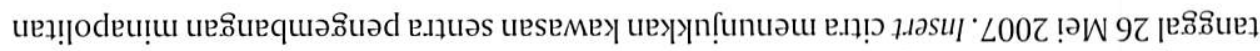

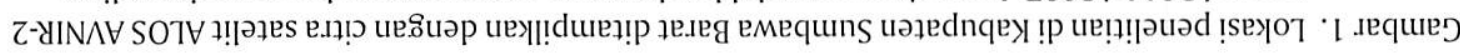

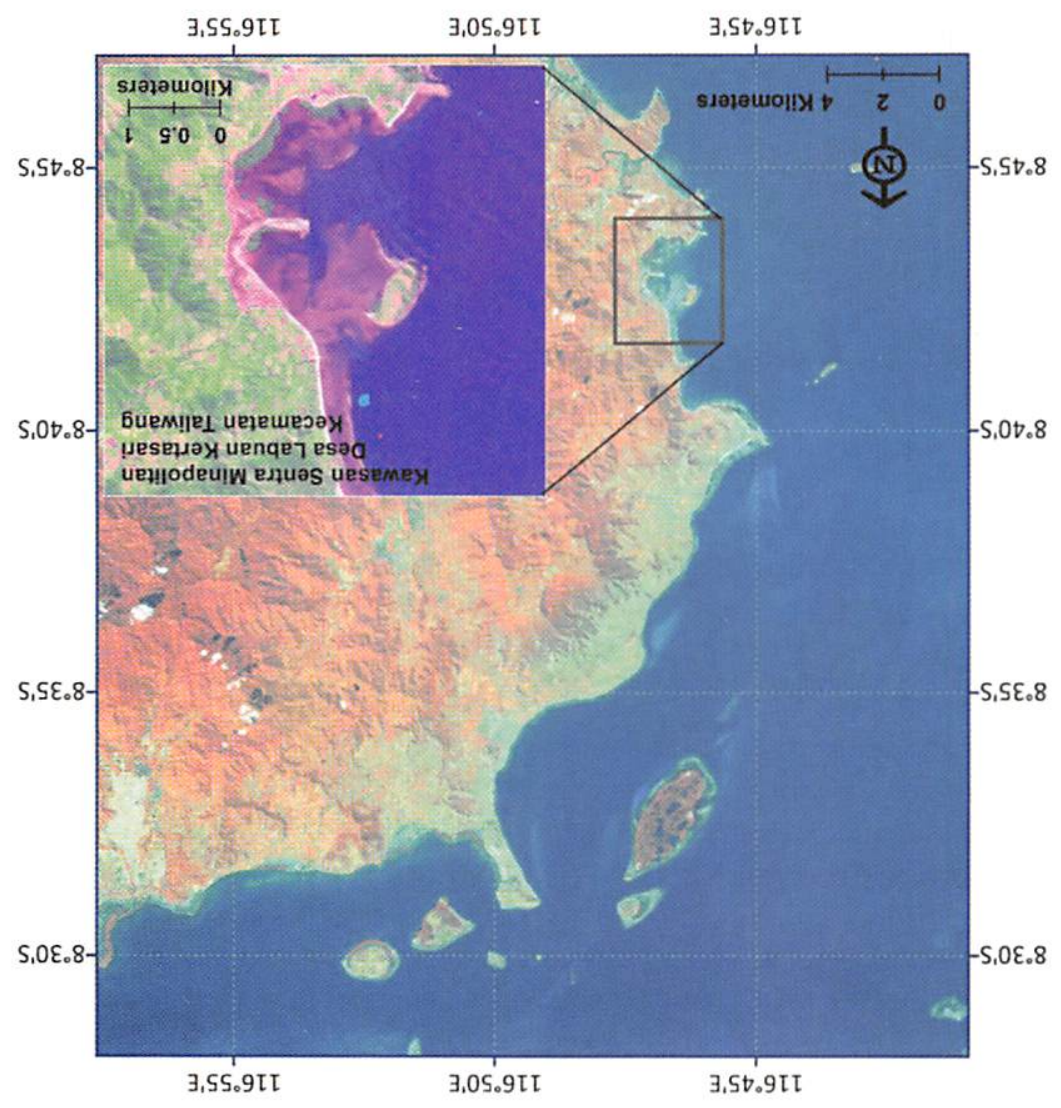


relatif rendah dibandingkan kisaran optimum untuk budidaya rumput laut yaitu $27^{\circ} \mathrm{C}-32^{\circ} \mathrm{C}$ (Tabel 1). Tingkat kecerahan perairan dan kedalaman perairan masih sesuai untuk budidaya rumput laut. Tingkat kecerahan yang direkomendasikan untuk budidaya rumput laut adalah $>3 \mathrm{~m}$ (Mubarak et al., 1990; Tiensongrusmee, 1986) atau $>5 \mathrm{~m}$ (Ariyati, 2007).

Ketersediaan nutrien yang dibutuhkan diperairan ditunjukkan oleh hasil pengukuran kandungan nitrat dengan kisaran $0,023-3,775 \mathrm{mg} /$ (Tabel 1). Nilai tersebut termasuk dalam kisaran yang sesuai untuk budidaya rumput laut yaitu $0,1-0,7 \mathrm{mg} / \mathrm{L}$ (Ariyati, 2007). Namun pada beberapa titik pengamatan diperoleh nilai pengukuran kandungan nitrat yang relatif rendah dari nilai yang seharusnya tersedia untuk pertumbuhan dan perkembangan rumput laut. Sebaliknya kandungan fosfat yang terukur berkisar antara $0,024-0,25 \mathrm{mg} / \mathrm{L}$. Kisaran nilai ini tergolong rendah dibandingkan nilai yang direkomendasikan yaitu $0,1-0,2 \mathrm{mg} / \mathrm{L}$ (Ariyati, 2007). Kisaran salinitas dan $\mathrm{pH}$ perairan yang terukur pada lokasi penelitian relatif masih dalam kisaran nilai yang sesuai untuk budidaya rumput laut (Tabel 1), yaitu salinitas berkisar $29-33$ ppt dan pH 7,0-8,5 (Ariyati, 2007). Salinitas, suhu dan $\mathrm{pH}$ perairan sangat dipengaruhi oleh air tawar yang masuk melalui muara sungai, sehingga dalam pemilihan lokasi budidaya harus mempertimbangkan jarak lokasi budidaya dengan masukan air tawar yang umumnya berasal dari muara sungai.

\section{Kondisi Infrastruktur, Kelembagaan, dan Sosial Masyarakat}

Keberhasilan aktivitas perikanan budidaya juga dipengaruhi oleh kondisi infrastruktur, kelembagaan, dan sosial masyarakat. Hasil pemantauan dilapangan dan wawancara dengan berbagai responden menunjukkan bahwa kondisi infrastruktur berupa jalan di kawasan minapolitan Sumbawa Barat umumnya dalam kondisi baik dan dapat dilalui oleh kendaraan roda empat. Kondisi ini sangat mendukung untuk aktivitas pengangkutan/ transportasi bibit dan bahan sarana produksi lainnya, serta pemasaran hasil panen. Keberadaan pelabuhan kapal di Desa Poto Tano juga sangat mendukung dalam hal transportasi produk budidaya antar pulau.

Kelembagaan yang terlibat dalam program minapolitan di Kabupaten Sumbawa Barat meliputi (Anonimous, 2011; Gambar 2: (1) koperasi "Depo Pasir Putih" (zona II), yang berfungsi sebagai pengelola depo kluster rumput laut dalam melaksanakan agribisnis rumput laut; (2) PT Indonusa Algaemas Prima (zona III), berperan sebagai pembeli produk rumput laut yang dihasilkan oleh pembudidaya; (3) yayasan pemberdayaan ekonomi Sumbawa Barat (YPESB-PT NTT) (zona III) yang membantu program pengembangan rumput laut melalui pendampingan dan pelatihan teknis serta dukungan pendanaan; (4) dewan harga (zona II), berperan menstabilkan harga produksi rumput laut di Kabupaten Sumbawa; dan (5) kelompok pembudidaya rumput laut (zona I). Keterlibatan kelima kelembagaan tersebut sangat mendukung keberhasilan pengembangan budidaya rumput laut di kabupaten ini.

Kondisi sosial masyarakat dilokasi ini sangat mendukung dalam pegembangan kawasan minapolitan khususnya untuk budidaya rumput laut. Masyarakat telah merasakan adanya peningkatan pola hidup dengan adanya aktivitas budidaya rumput laut ini. Budidaya rumput laut yang dilakukan umumnya merupakan mata pencaharian sampingan/alternatif, namun ada juga yang menjadikan sebagai mata pencaharian utama. Mata pencaharian masyarakat selain budidaya rumput laut

Tabel 1. Kisaran parameter kualitas perairan di kawasan minapolitan Kabupaten Sumbawa Barat Provinsi Nusa Tenggara Barat

Table 1. Range of water quality measurement in minapolitan area of West Sumbawa District West Nusa Tenggara Province

\begin{tabular}{lcc}
\hline \multicolumn{1}{c}{ Peubah (Parameter) } & Satuan (Units) & Kisaran (Range) \\
\hline Kecerahan (Transparency) & $\mathrm{m}$ & $0,8-14$ \\
Kedalaman (Water depth) & $\mathrm{m}$ & $0,8-25,5$ \\
Suhu (Temperature) & ${ }^{\circ} \mathrm{C}$ & $26,24-27,74$ \\
Total dissolve solid (TDS) & $\mathrm{g} / \mathrm{L}$ & $32,54-33,11$ \\
Salinitas (Salinity) & $\mathrm{psu}$ & $32,77-33,38$ \\
Oksigen terlarut (Dissolve oxygen) & $\mathrm{mg} / \mathrm{L}$ & $6,23-8,35$ \\
Bahan organik total (Total organic matter) & $\mathrm{mg} / \mathrm{L}$ & $25,87-52,27$ \\
$\mathrm{pH}$ & & $7,01-8,56$ \\
$\mathrm{NO}_{3}-\mathrm{N}$ & $\mathrm{mg} / \mathrm{L}$ & $0,023-3,775$ \\
$\mathrm{NO}_{2}-\mathrm{N}$ & $\mathrm{mg} / \mathrm{L}$ & $<0,0008$ \\
$\mathrm{NH}_{3}-\mathrm{N}$ & $\mathrm{mg} / \mathrm{L}$ & $0,073-0,439$ \\
$\mathrm{PO}_{4}-\mathrm{P}$ & $\mathrm{mg} / \mathrm{L}$ & $0,024-0,25$ \\
$\mathrm{SiO}_{2}$ & $\mathrm{mg} / \mathrm{L}$ & $0,0018-0,0138$ \\
$\mathrm{Fe}^{2+}$ & $\mathrm{mg} / \mathrm{L}$ & $0-0,007$ \\
\hline
\end{tabular}




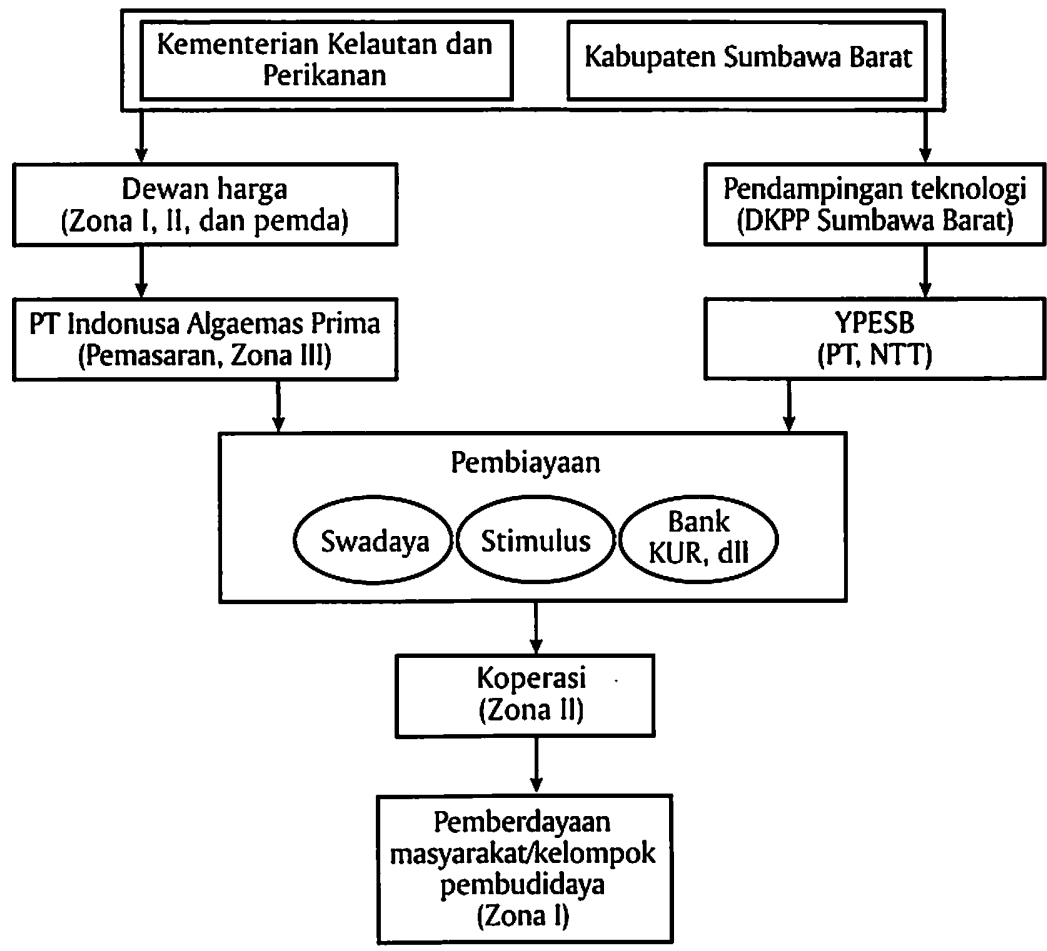

Gambar 2. Sistem kelembagaan pengembangan rumput laut di Kabupaten Sumbawa Barat Provinsi Nusa Tenggara

Figure 2. Institutional network for seaweed aquaculture development in West Sumbawa District West Nusa Tenggara Province

yaitu sebagai petani, peternak, dan nelayan. Dalam pelaksanaan di lapangan keterlibatan wanita juga sangat besar, terutama pada proses persiapan budidaya dan pemanenan .

\section{Kesesuaian Lahan Budidaya}

Beberapa parameter penting kualitas air dipilih sebagai kriteria analisis spasial untuk menentukan sebaran dan tingkat kesesuaian lahan budidaya rumput laut dengan sistem apung dan lepas dasar (Radiarta et al., 2011). Hasil analisis spasial untuk pengembangan kawasan budidaya rumput laut di Kabupaten Sumbawa Barat, dari total area potensial seluas 16.846 ha diperoleh hasil tiga tingkat kesesuaian lahan yaitu $43,8 \%$ sangat sesuai, $54,9 \%$ sesuai, dan $1,3 \%$ cukup sesuai untuk sistem lepas dasar. Untuk sistem apung diperoleh luas lahan yang sangat sesuai sebesar $46,8 \%$; sesuai $52,0 \%$; dan cukup sesuai $0,2 \%$. Kajian kesesuaian lahan pada penelitian ini telah menggabungkan berbagai parameter penting yang berpengaruh terhadap kegiatan budidaya rumput laut meliputi kualitas air dan infrastruktur. Hasil analisis dari penelitian ini dapat dipertajam lagi dengan menambahkan parameter penting lainnya baik dari aspek kualitas perairan (kecepatan arus, keterlindungan, dan tinggi gelombang), sosial ekonomi (aspek tata ruang dan pemasaran ketersediaan benih) maupun aspek lainnya seperti sarana pengolahan produk dan ketersediaan suplai bibit. Menurut Kingzet et al. (2002), analisis kelayakan lahan untuk budidaya laut harus memperhatikan dua kategori utama yaitu kondisi lingkungan perairan yang dapat mendukung pertumbuhan biota; dan kondisi sosial-ekonomi, serta ketersediaan infrastruktur penunjang yang dapat mendukung kelangsungan kegiatan budidaya laut tersebut.

Analisis spasial yang dilakukan pada lokasi penelitian ini menunjukkan hasil yang sangat relevan dengan penetapan Kecamatan Taliwang sebagai sentra pengembangan minapolitan. Hasil analisis ini diharapkan dapat menjadi acuan bagi pengembangan budidaya rumput laut untuk mendukung kesuksesan program minapolitan di Kabupaten Sumbawa Barat. Dalam implementasi kegiatan budidaya rumput laut di lapangan, komunikasi dengan para pihak terkait (stakeholder) perlu dimaksimalkan guna mendukung kegiatan budidaya rumput laut yang berkelanjutan (Stead et al., 2002).

\section{Strategi Pengembangan Minapolitan}

Minapolitan dilaksanakan melalui pengembangan kawasan unggulan. Kawasan minapolitan dikembangkan melalui pembinaan sentra produksi yang berbasis pada sumberdaya kelautan dan perikanan. Dengan pendekatan sentra produksi, sumberdaya yang dibutuhkan baik berupa prasarana dan sarana produksi, anggaran, dan permodalan, dapat dikonsentrasikan di lokasi-lokasi potensial, sehingga peningkatan produksi kelautan dan perikanan dapat dipacu lebih cepat. Kesuksesan pelaksanaan minapolitan di Kabupaten Sumbawa Barat harus didukung sepenuhnya oleh berbagai pihak diantaranya pemerintah daerah, pengusaha, perbankan, dan pembudidaya. Karakteristik perairan di kabupaten ini 


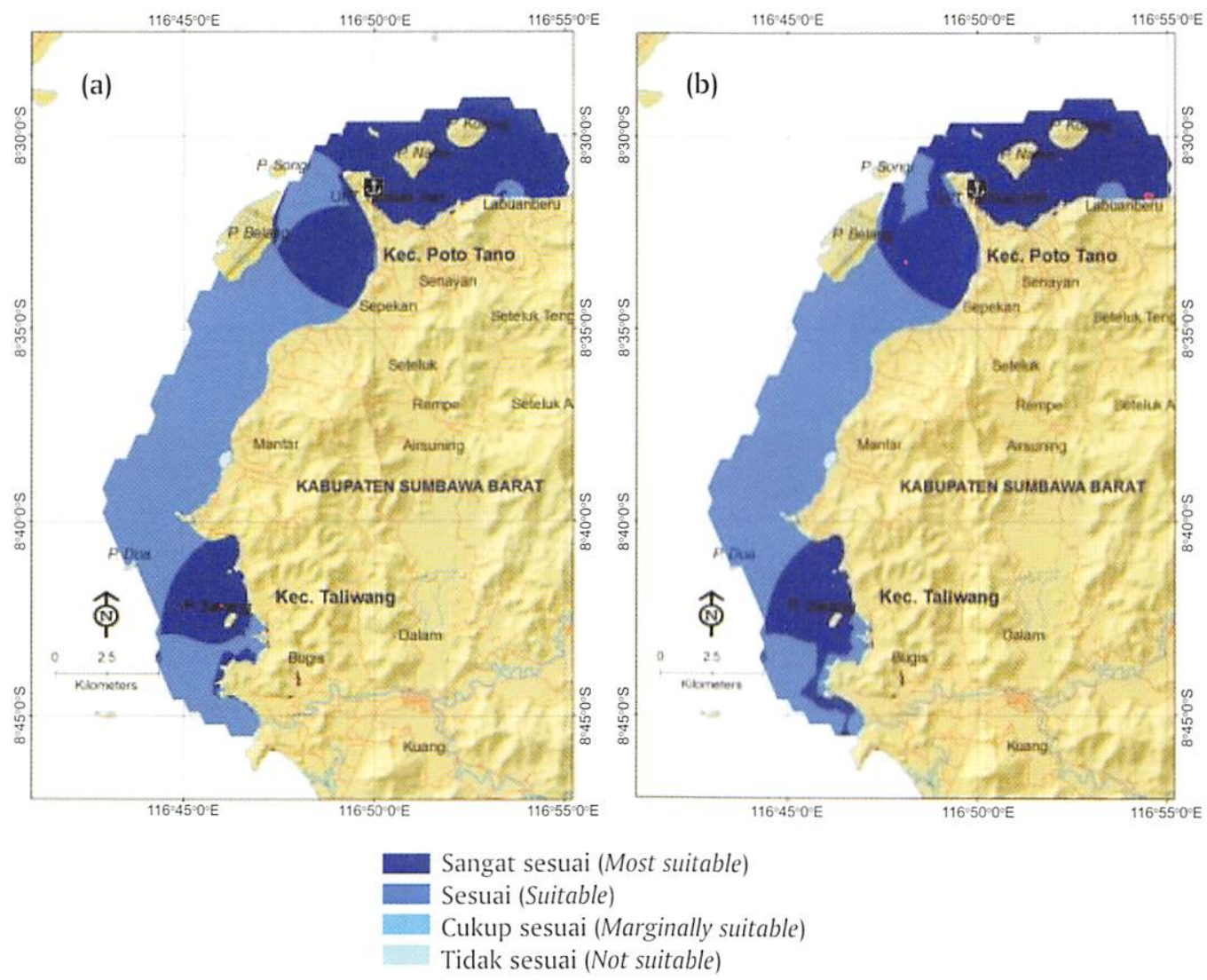

Gambar 3. Peta kesesuaian lahan budidaya rumput laut sistem lepas dasar (a) dan apung (b) di kawasan minapolitan Kabupaten Sumbawa Barat Provinsi Nusa Tenggara Barat

Figure 3. Map of suitability site for seaweed aquaculture using off-bottom culture (a) and long line culture (b) systems in minapolitan area of West Sumbawa District West Nusa Tenggara Province

bukan menjadi faktor penghambat (Tabel 1), namun sebaliknya merupakan faktor pendukung pelaksanaan minapolitan. Beberapa permasalahan yang diidentifikasi selama survai diantaranya; ketersediaan bibit rumput laut yang tidak berkesinambungan, pemilihan lokasi yang kurang sesuai untuk budidaya rumput laut, dan lemahnya penerapan teknologi budidaya yang belum disesuaikan dengan daya dukung lahan, pola tanam, dan pengaturan tata ruang.

Strategi yang dapat dilakukan guna memperkecil atau bahkan menghilangkan hambatan yang muncul dalam pengembangan kawasan minapolitan budidaya rumput laut dapat dilakukan melalui beberapa langkah yaitu:

1) Penentuan lokasi kebun bibit rumput laut yang memiliki karakteristik lingkungan perairan yang mendukung, sehingga bibit dapat tumbuh dan berkembang dengan baik sepanjang tahun.

2) Identifikasi dan penentuan musim tanam sehingga dapat meningkatkan produksi yang maksimal sesuai dengan karakteristik lokasi.

3) Penerapan tata guna lahan yang sesuai, yang disusun berdasarkan hasil kajian secara ilmiah. Tata guna lahan ini harus disosialisasikan kepada pembudidaya, sehingga dapat mendukung pelaksanaan budidaya rumput laut untuk mendukung keberlanjutan usaha budidaya masyarakat.

4) Peran penyuluh dan Dinas Kelautan dan Perikanan setempat perlu ditingkatkan terkait dengan penerapan teknologi yang sesuai dengan karakteristik lokasi. Bimbingan teknis ataupun studi banding ke wilayah lain perlu dilakukan guna memberikan wawasan kepada pembudidaya tentang bagaimana cara menerapkan teknologi budidaya yang baik dan benar sesuai dengan karakteristik lokasi. Peran pemerintah pusat melalui institusi penelitian juga dapat dilaksanakan, di antaranya melalui program IPTEKMAS (ilmu pengetahuan dan teknologi untuk masyarakat) yang dilaksanakan oleh Pusat Penelitian dan Pengembangan Perikanan Budidaya, Badan Penelitian dan Pengembangan Kelautan dan Perikanan, Kementerian Kelautan dan Perikanan.

\section{KESIMPULAN}

Kabupaten Sumbawa Barat merupakan wilayah percontohan nasional kawasan minapolitan rumput laut (Kappaphycus alvarezii). Melalui dukungan pemda setempat, telah ditetapkan lokasi pengembangannya yaitu Desa Labuhan Kertasari, Kecamatan Taliwang sebagai sentra pengembangan budidaya rumput laut degan metode 
lepas dasar. Kualitas perairan di Kabupaten Sumbawa Barat masih sangat mendukung pengembangan budidaya rumput laut. Kondisi infrastruktur dan kelembagaan umumnya juga relatif kondusif. Hasil analisis spasial dari total area potensial untuk budidaya rumput laut seluas 16.846 ha, tingkat kesesuaian lahan budidaya rumput laut sistem lepas dasar di perairan sekitar Kabupaten Sumbawa Barat yaitu sangat sesuai sebesar 43,84\%; sedangkan untuk budidaya dengan sistem apung, luas lahan yang sangat sesuai mencapai $46,77 \%$. Sebaran tingkat kesesuaian lahan ini relatif mempunyai pola yang serupa antara sistem lepas dasar dan apung, dengan tingkat kesesuaian yang sangat sesuai menyebar di bagian barat dan utara lokasi penelitian. Analisis ini relevan dengan perencanaan pemerintah daerah yang menetapkan Kecamatan Taliwang sebagai sentra pengembangan minapolitan.

\section{UCAPAN TERIMA KASIH}

Penulis mengucapkan terima kasih kepada Dinas Kelautan dan Perikanan Kabupaten Sumbawa Barat atas bantuannya selama kegiatan lapangan. Kami juga mengucapkan terima kasih kepada semua tim survai minapolitan: Prof. Achmad Sudradjat, Prof. Akhmad Mustafa, Mudian Paena, Hasnawi, dan Rizky Antoni yang telah membantu kelancaran pengumpulan data lapangan. Penelitian ini merupakan bagian dari penelitian Kajian Kesesuaian Lahan untuk Minapolitan Pusat Penelitian dan Pengembangan Perikanan Budidaya T.A 2011.

\section{DAFTARACUAN}

Aguilar-Manjarrez, J., Kapetsky, J.M., \& Soto, V. (2010). The potential of spatial planning tools to support the ecosystem approach to aquaculture. FAO/Rome. Expert Workshop. 19-21 November 2008, Rome, Italy. FAO Fisheries and Aquaculture Proceedings. No.17. Rome. $176 \mathrm{pp}$.

Anonimous. (2011). Data dan informasi minapolitan industri rumput laut Kabupaten Sumbawa Barat. Dinas Kelautan Perikanan dan Peternakan, Kabupaten Sumbawa Barat, Provinsi Nusa Tenggara Barat. 20 hal.
Ariyati, R.W., Sya'rani, L., \& Arini, E. (2007). Analisis kesesuaian perairan pulau Karimunjawa dan pulau Kemujan sebagai lahan budidaya rumput laut menggunakan sistem informasi geografis. Jurnal Pasir Laut, 3(1), 27-45.

Burrough, P.A., \& McDonnell, R.A. (1998). Principle of geographical information systems. Oxford University Press, $327 \mathrm{pp}$.

BPS Sumbawa Barat. (2010). Sumbawa Barat dalam angka 2010. Badan Pusat Statistik Kabupaten Sumbawa Barat, $507 \mathrm{hlm}$.

Ditjen Perikanan Budidaya. (2010). Statistik perikanan budidaya Indonesia. Kementerian Kelautan dan Perikanan. Direktorat Jenderal Perikanan Budidaya, Jakarta, 141 hlm.

Mustafa, A., Radiarta, I N., \& Syah, R. (2011). Profile dan kesesuaian lahan akuakultur mendukung minapoilitan. Pusat Penelitian dan Pengembangan Perikanan Budidaya. Badan Litbang Kelautan dan Perikanan.

Kapetsky, J.M., \& Anguilar-Manjarrez, J. (2007). Geographic information systems, remote sensing and mapping for the development and management of marine aquaculture. FAO Fish. Tech. Pap. No. 458. Rome, 125 pp.

Kingzet, B., Salmon, R., \& Canessa, R. (2002). First nations shellfish aquaculture regional business strategy. $B C$ central and northern coast. Aboriginal relations and economic measures, Land and Water British Columbia Inc., 256 pp.

Mubarak, H., llyas, S., Ismail, W., Wahyuni, I.S., Hartati, S.H., Pratiwi, E., Jangkaru, Z., \& Arifuddin, R. (1990). Petunjuk teknis budidaya rumput laut. Badan Litbang Pertanian, Puslitbang Perikanan. IDRC, Infish, $93 \mathrm{hlm}$.

Radiarta, I N., Sudradjat, A., Paena, M., Hasnawi, Mustafa, A., \& Antoni, R. (2011). Analisis kesesuaian lahan budidaya rumput laut di kawasan minapolitan Kabupaten Sumbawa Barat, Provinsi Nusa Tenggara Barat. Laporan kegiatan penelitian. Pusat Penelitian dan Pengembangan Perikanan Budidaya, Jakarta, $27 \mathrm{hlm}$.

Stead, S.M., Burnell, G., \& Goulletquer, P. (2002). Aquaculture and its role in integrated coastal zone management. Aquaculture International, 10, 447-468. 